\title{
Correction to: Oxidation-Enhanced Evaporation in High-Carbon Ferromanganese
}

\section{Håkon Aleksander Hartvedt Olsen Myklebust ${ }^{1}$ (D) Stefan Andersson $^{2}$. Gabriella Tranell ${ }^{1}$}

Published online: 19 April 2021

(c) Springer Science+Business Media, LLC, part of Springer Nature 2021

\section{Correction to: Oxidation of Metals https://doi.org/10.1007/s11085-021-10023-0}

The original version of the article unfortunately contained an error in the corresponding author's name. Instead of "Håkon Aleksander Hartvedt Olsen Myklebust" it has been wrongly displayed as "Hn Aleksander Hartvedt Olsen Myklebust". This has been corrected by publishing this correction article. The original article has been updated.

Publisher's Note Springer Nature remains neutral with regard to jurisdictional claims in published maps and institutional affiliations.

The original article can be found online at https://doi.org/10.1007/s11085-021-10023-0.

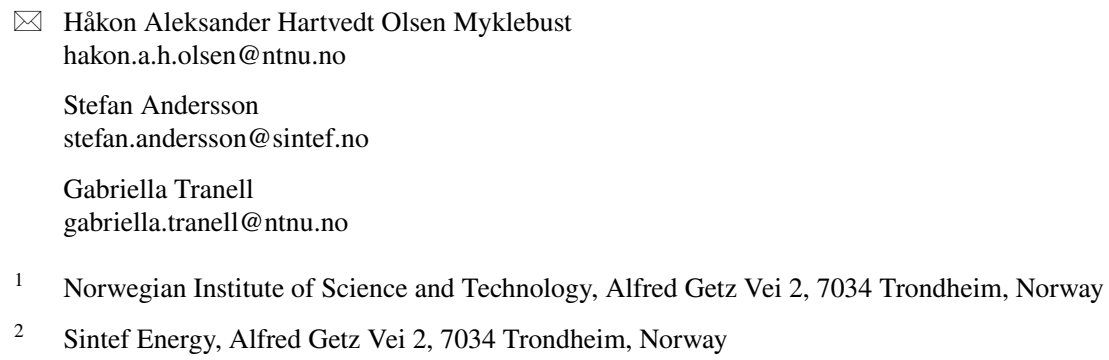

